OPEN ACCESS

Edited by:

Yasushi Takagi,

Tokushima University, Japan

Reviewed by:

Yohei Mineharu,

Kyoto University, Japan

Yoshio Araki,

Nagoya University Graduate School of

Medicine, Japan

Hitoshi Fukuda,

Kochi University, Japan

*Correspondence:

$\mathrm{Hao} \mathrm{Nie}$

niehxhust@foxmail.com

Zhouping Tang

ddjtzp@163.com

Specialty section:

This article was submitted to

Stroke,

a section of the journal

Frontiers in Neurology

Received: 10 December 2020 Accepted: 08 February 2021

Published: 02 March 2021

Citation:

Chen D, Zhang G, Wang J, Chen S,

Wang J, Nie H and Tang Z (2021)

Mapping Trends in Moyamoya

Angiopathy Research: A 10-Year

Bibliometric and Visualization-Based

Analyses of the Web of Science Core

Collection (WoSCC).

Front. Neurol. 12:637310.

doi: 10.3389/fneur.2021.637310

\section{Mapping Trends in Moyamoya Angiopathy Research: A 10-Year Bibliometric and Visualization-Based Analyses of the Web of Science Core Collection (WoSCC)}

\author{
Danyang Chen ${ }^{1}$, Ge Zhang ${ }^{1}$, Jiahui Wang ${ }^{1}$, Shiling Chen ${ }^{1}$, Jingxuan Wang ${ }^{1}$, Hao Nie ${ }^{2 \star}$ and \\ Zhouping Tang ${ }^{1 *}$
}

\footnotetext{
${ }^{1}$ Department of Neurology, Tongji Hospital, Tongji Medical College, Huazhong University of Science and Technology, Wuhan Hubei, China, ${ }^{2}$ Department of Geriatrics, Tongji Hospital, Tongji Medical College, Huazhong University of Science and Technology, Wuhan, China
}

Background: Moyamoya angiopathy (MMA), which includes moyamoya disease (MMD) and moyamoya syndrome (MMS), is an uncommon cerebrovascular condition characterized by recurrent stroke. We carried out a bibliometric analysis to examine the development of and research trends in MMA research.

Methods: Studies published between 2010 and 2019 on MMA were retrieved from the Web of Science Core Collection (WoSCC) on August 14, 2020, and bibliometric and visualization-based analyses were performed by using three different scientometric tools: HistCite, VOSviewer, and CiteSpace.

Results: A total of 1,896 publications published in 384 journals by 6,744 authors, 1,641 institutions and 56 countries/regions were included in the analyses. Annual publication outputs increased from 2010 to 2019. The USA, Japan and China were three key contributors to this study field. Capital Medical University, Seoul National University, and Stanford University were three major institutions with larger numbers of publications. Zhang D, World Neurosurgery, Kuroda S, and STROKE were the most prolific author, prolific journal, top co-cited author and top co-cited journal, respectively. The top five keywords during this period were moyamoya disease, revascularization, stroke, children and surgery, while revascularization surgery and RNF213 were the most common frontier topics.

Conclusions: In this study, the research trends of global scientific research on MMA over the past decade were systematically analyzed. The study can provide guidance for scholars who want to understand current trends in research in this area and new research frontiers.

Keywords: bibliometrics, CiteSpace, emerging topics, visualization, HistCite, VOSviewer, moyamoya, Web of Science 


\section{INTRODUCTION}

Moyamoya angiopathy (MMA) is an infrequent, chronic, and disabling cerebrovascular condition. Clinical features include ongoing stenosis and occlusion of the distal part of internal carotid arteries and the proliferation of moyamoya-associated collaterals $(1,2)$. MMA can be divided into moyamoya disease (MMD) and moyamoya syndrome (MMS). The specific pathological mechanism of MMA remains unclear (3). Revascularization surgery is an effective MMA treatment (2).

In the field of bibliometrics, quantitative and visualizationbased analyses were performed on scientific publication data and citation data $(4,5)$. Through the quantitative analysis of publications available in a library, the research trends in a specific field can be investigated. The Web of Science Core Collection (WoSCC) is the most commonly used database in bibliometric studies (6). Scientometric applications used in bibliometric studies include HistCite (7), VOSviewer (8), and CiteSpace (9). For the past few years, bibliometric analysis has been applied in various biomedical fields (10-12).

As far as we know, no published bibliometric study has focused on MMA research. Here, we visually analyzed the development of and trends in MMA research from 2010 to 2019 using HistCite, VOSviewer, and CiteSpace.

\section{MATERIALS AND METHODS}

\section{Data Source and Information Retrieval Strategy}

A literature search was carried out by using the WoSCC database to collect publications on MMA. All data obtained were appropriate for the bibliometric analysis. All searches were performed under identical conditions to minimize the bias on August 14,2020. The search strategy was unanimously agreed on by all members of our research team. The advanced search was conducted using the following formula: TS = ("moyamoya"). The detailed search processes and analysis procedures were shown in Figure 1 (13).

\section{Inclusion Criteria}

(a) Peer-Reviewed Articles on MMA

(b) Documents types: articles, reviews, letters, and proceeding papers

(c) Year of publication: 2010-2019

(d) Language type: all languages

(e) Database: Web of Science Core Collection (WoSCC).

\section{Exclusion Criteria}

(a) Articles that required a manual search

(b) Unpublished papers.

\section{Statistical and Analytical Methods}

The full records and cited references of identified publications were exported as plain text and tab-delimited (Win, UTF-8) files for bibliometric analysis and visualization. HistCite (Clarivate Analytics, Philadelphia, PA, USA), CiteSpace 5.3.R4 (Drexel University, Philadelphia, USA) and VOSviewer 1.6.14 (Leiden
University, Leiden, Netherlands) were used for data analysis. HistCite is a program used to quickly summarize and analyse publications. In this study, HistCite was applied to confirm annual output, total number of citations, language type and document type. VOSviewer was employed to construct visual maps and summarize prolific countries/regions, institutions, journals, and authors, as well as the top co-cited journals, authors, keywords and references. For VOSviewer, the full counting method was used, and the minimum threshold of the data selected to construct the visual maps depended on specific items such as the institution or journal. CiteSpace, which runs in a Java environment, was used to construct the category map and detect the burst terms of keywords and co-cited references. The parameters used with CiteSpace were set as follows: time slice (2010-2019 by year), text processing (term source: all selection), term type (burst terms), node type (set based on the item), links (strength: cosine; scope: within slices), selection criteria (top 50 objects), and pruning (pathfinder and pruning sliced networks). The linear forecasting model can be described as $f(x)=a x+b$, where $x$ is the publication year and $f(x)$ is the number of publications. The linear fit of the annual number of publications by year was graphed using GraphPad Prism 8 (GraphPad Software, San Diego, CA, USA), and the output was predicted for 2020. Pearson's correlation analysis of the year and annual output was conducted using IBM SPSS Statistics 25.0 software (SPSS Inc., Chicago, USA). Journal impact factors (IFs) were identified according to the 2019 Journal Citation Reports (JCR) released by Clarivate Analytics on June 29, 2020.

A review of ethics was unnecessary because all original data used in this study were from a public database.

\section{RESULTS}

\section{General Publication Data and the Upward Trend of Annual Output}

A total of 1,896 studies published from 2010 to 2019 were used for our bibliometric data analysis. The studies were published in 384 journals by 6,744 authors, 1,641 institutions and 56 countries/regions. There were 20,050 citations in total. The article was the primary document type $(n=1,552,81.86 \%)$, followed by the review ( $n=208,10.97 \%)$, letter $(n=132,6.96 \%)$, and proceedings paper $(n=4,0.21 \%)$. Languages included English $(n=1,873,98.79 \%)$, French $(n=10,0.53 \%)$, German $(n=$ 7, 0.37\%), and Spanish $(n=6,0.32 \%)$. Three Eastern Asian languages Japanese, Korean and Chinese, were not included in the database.

It was suggested that the annual output varied by years, and there was a slight increase in output over the last 10 years (Figure 2A). The most prolific year was 2019, in which 273 papers were published, and the minimum output occurred in $2011(n=121,6.38 \%)$. In terms of total citations, there was a peak in $2014(n=2,899)$ (Figure 2A), and $2013(n=163$, GR $=14.79 \%), 2014(n=194, \mathrm{GR}=19.02 \%), 2016(n=218, \mathrm{GR}$ $=11.22 \%)$, and $2019(n=273, \mathrm{GR}=15.68 \%)$ were considered "remarkable" years (14) [note that a year is defined as remarkable 


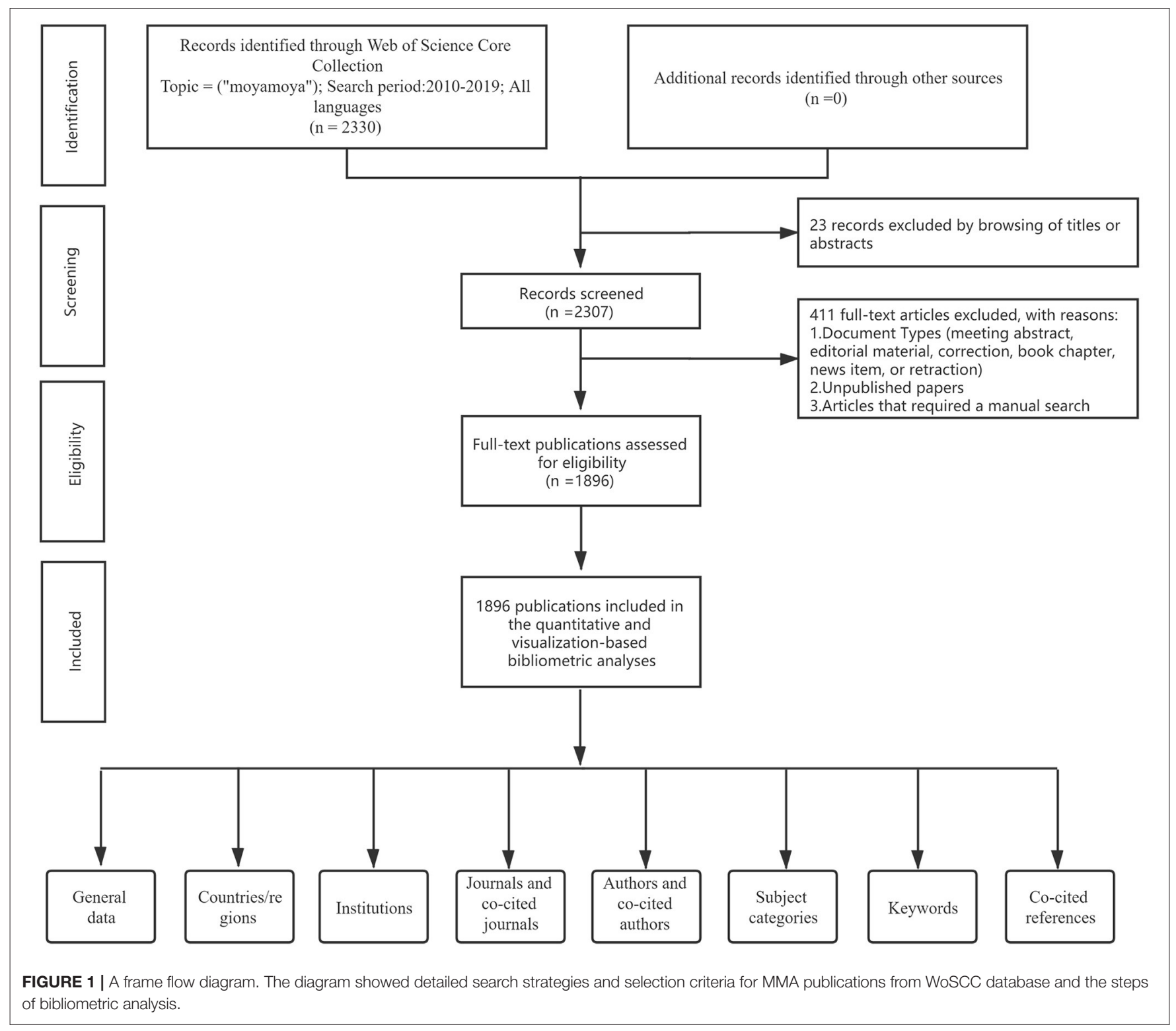

if more than 150 papers were published and if there was a year-over-year growth rate (GR) $>10 \%$ (Figure 2B)].

Pearson's correlation analysis showed that the annual output was positively correlated with the year $(r=0.983, P<0.0001)$, and the linear fit (Figure 2C) between the year and the number of published MMA studies was significantly correlated $\left(R^{2}=\right.$ 0.9654, $P<0.0001)$. According to the mathematical model, publication output will reach 279 in 2020.

\section{Countries/Regions}

A total of 56 countries/regions contributed to the published MMA research $(n=1,896)$. The USA $(n=473,24.95 \%)$ was the most prolific country/region. The top 10 productive countries/regions were shown in Table 1. A co-authorship network was constructed for the countries/regions using
VOSviewer. The map of the co-authorship network (Figure 3) includes 23 countries, and the smallest node has 6 publications. The USA, Japan, China, and South Korea were represented by the four largest nodes, which is consistent with the result in Table 1. The USA had the strongest collaboration network, with the maximum total link strength (TLS $=127$ ). The strongest collaboration networks were between the USA and China (TLS $=21$ ) and between the USA and Canada (TLS $=21)$.

\section{Institutions}

The top 10 institutions in terms of productivity were presented in Table 2. Among these institutions, Capital Medical University (China, 95 publications) was the most prolific institution, followed by Seoul National University (South 


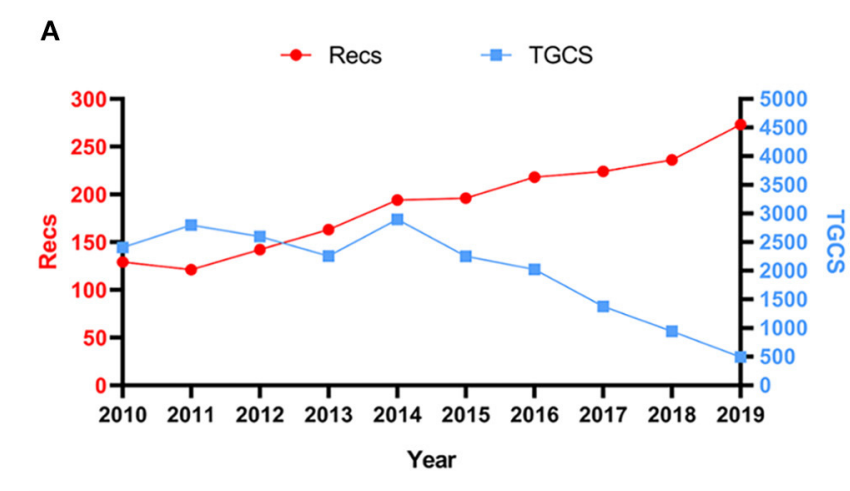

C

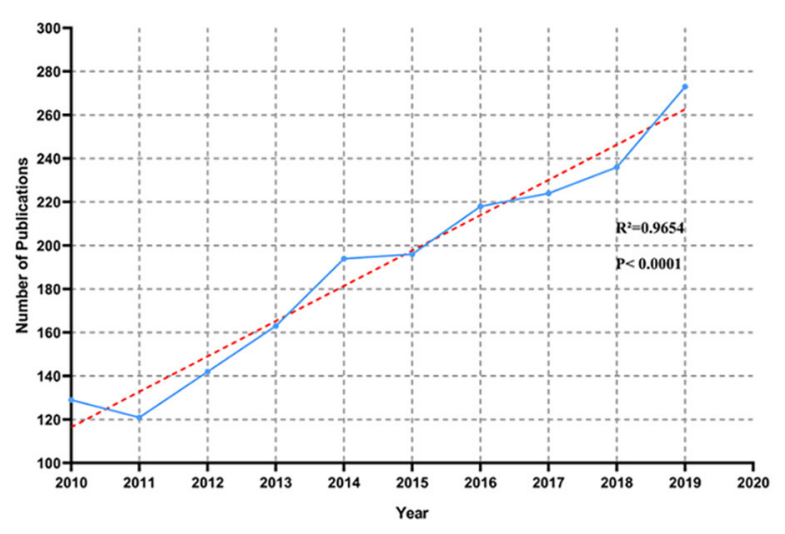

B

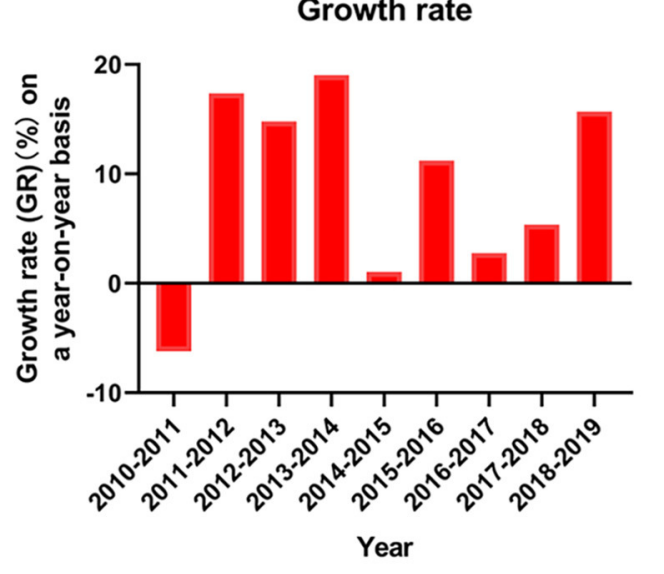

FIGURE 2 | (A,B) The annual output, citations and growth rate on a year-on-year basis with regard to MMA during 2010-2019. (C) The linear model of the upward trend in the field of MMA $\left(R^{2}=0.9654, P<0.0001\right)$. Recs: Number of Records, namely the number of publications for a given year; TGCS: Total Global Citation Score, namely the total count of citations.

TABLE 1 | The top 10 countries according to total publications during 2010-2019.

\begin{tabular}{clcccc}
\hline Rank & Country & $\begin{array}{c}\text { Number of } \\
\text { publications }\end{array}$ & Proportion (\%) & $\begin{array}{c}\text { Total } \\
\text { citations }\end{array}$ & $\begin{array}{c}\text { Citations/ } \\
\text { paper }\end{array}$ \\
\hline 1 & The USA & 473 & $24.95 \%$ & 5,892 & $12.5(7)$ \\
2 & Japan & 458 & $24.16 \%$ & 5,906 & $12.9(5)$ \\
3 & China & 347 & $18.30 \%$ & 2,993 & $8.6(8)$ \\
4 & South Korea & 231 & $12.18 \%$ & 3,205 & $13.9(3)$ \\
5 & Germany & 102 & $5.38 \%$ & 1,304 & $12.8(6)$ \\
6 & Canada & 72 & $3.80 \%$ & 1,308 & $18.2(1)$ \\
7 & India & 62 & $3.27 \%$ & 191 & $3.1(10)$ \\
8 & France & 59 & $3.11 \%$ & 766 & $13(4)$ \\
9 & England & 51 & $2.69 \%$ & 745 & $14.6(2)$ \\
10 & Italy & 47 & $2.48 \%$ & 341 & $7.3(9)$ \\
\hline
\end{tabular}

Data were retrieved from 1,896 publications with VOSviewer on August 14, 2020.

Korea, 84 publications) and Stanford University (the USA, 71 publications). In terms of citations, Tohoku University (Japan, 1,633 times), Seoul National University (South Korea, 1,453 times), Kyoto University (Japan, 1,408 times) and Stanford University (the USA, 1,300 times) exceeded 1,000 citations. Cooperative relationship among 63 institutions is shown in Figure 4. The co-authorship institutional analysis network

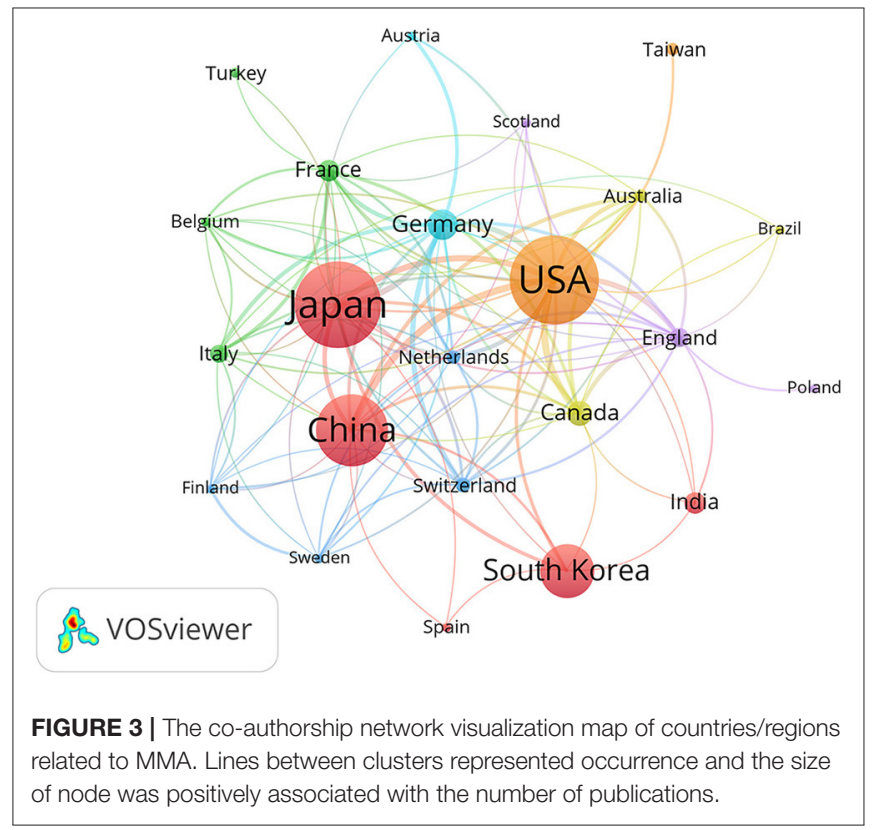

had a minimum threshold of 10 publications. As shown in the network map, a variety of institutions closely cooperation with each other. 


\section{Journals and Co-cited Journals}

Peer-reviewed journals publishing literature on MMA were identified with VOSviewer $(n=384)$. The top 10 journals and co-cited journals were shown in Table 3. The top 10 journals

TABLE 2 | The top 10 most productive institutions between 2010 and 2019.

\begin{tabular}{clccl}
\hline & \multicolumn{1}{c}{ 2010-2019 } & & & \\
\cline { 2 - 4 } Rank & The name of institution & Publications & Citations & Location \\
\cline { 5 - 5 } 1 & Capital Med Univ & 95 & 661 & China \\
2 & Seoul Natl Univ & 84 & 1,453 & Korea \\
3 & Stanford Univ & 71 & 1,300 & The USA \\
4 & Tohoku Univ & 63 & 1,633 & Japan \\
5 & Kyoto Univ & 57 & 1,408 & Japan \\
6 & Hokkaido Univ & 55 & 821 & Japan \\
7 & Beijing Inst Brain Disorders & 45 & 221 & China \\
8 & Sungkyunkwan Univ & 41 & 703 & Korea \\
9 & Natl Cerebral \& Cardiovasc Ctr & 39 & 994 & Japan \\
10 & China Natl Clin Res Ctr Neurol Dis & 37 & 187 & China \\
\hline
\end{tabular}

Data were retrieved from 1,896 publications with VOSviewer on August 14, 2020. in terms of productivity collectively produced 714 publications, accounting for $37.7 \%$ of all papers, and STROKE had the highest impact factor ( $\mathrm{IF}=7.19$ ). World Neurosurgery was the most prolific journal, with 168 publications. The top 3 cocited journals were as follows: STROKE (5,721 co-citations), Journal of Neurosurgery (3,289 co-citations) and Neurosurgery (2,410 co-citations).

\section{Authors and Co-cited Authors}

A total of 6,744 authors contributed to MMA-related research, with an average of 3.6 authors per study. The top 12 contributing authors involved in the research were listed in Table 4. Zhang D was the most prolific author, with 61 publications, followed by Tominaga $\mathrm{T}(n=59)$ and Fujimura $\mathrm{M}(n=52)$. Co-cited authors were authors who have been co-cited in publications, and cocitation is a key measurement of the contribution degree of an author. The top 12 co-cited authors were shown in Table 4.

Visual maps of authors and co-cited authors can effectively display powerful research teams and potential partners (15). A co-authorship analysis of authors was carried out by VOSviewer. The minimum number of publications of each author was set to 10, and 106 authors were screened. Among them, some authors were not connected to others. To improve the visualization, the largest subnetwork (67 authors) was identified, as illustrated

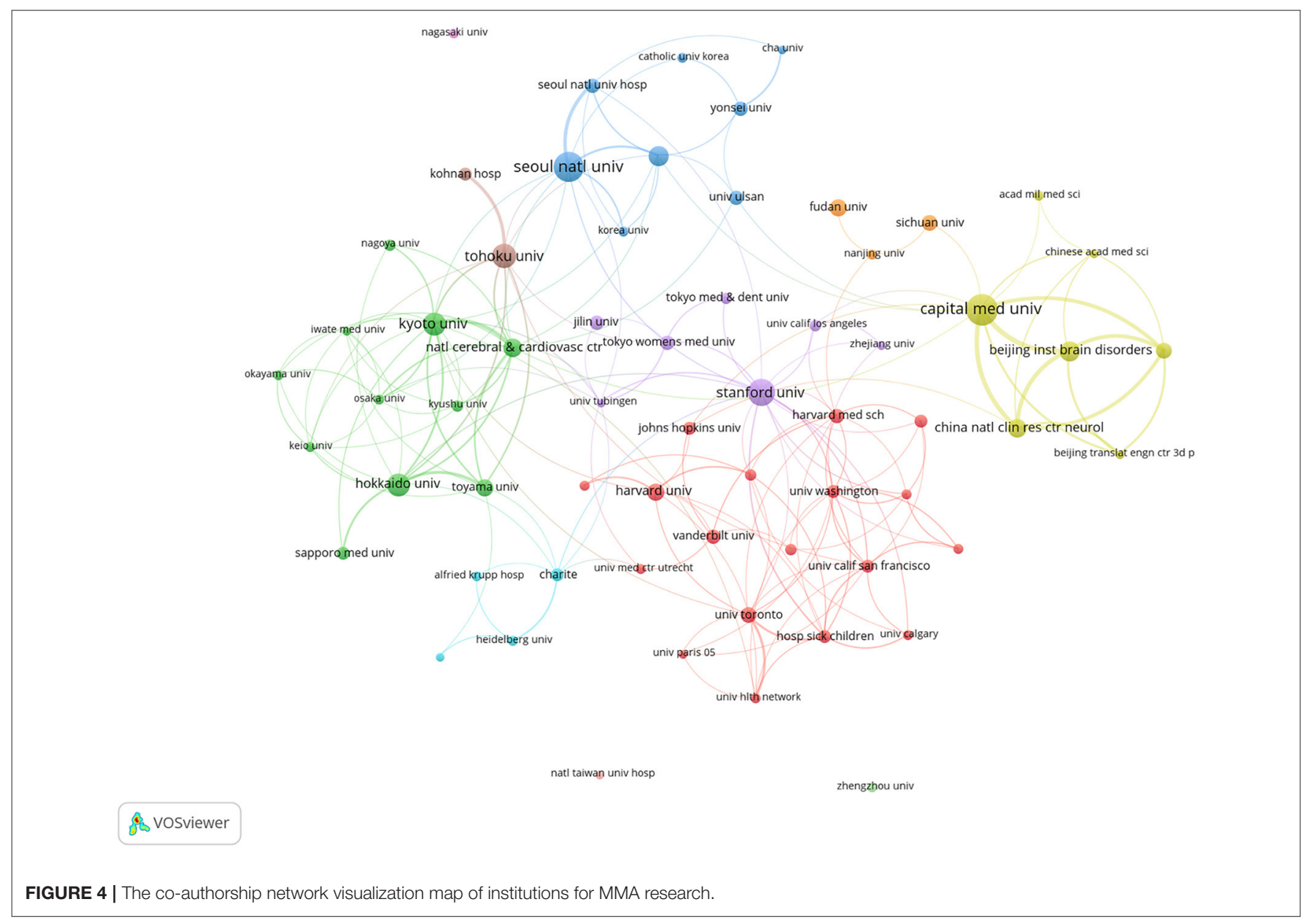


TABLE 3 | The top 10 journals and co-cited journals on MMA research between 2010 and 2019.

\begin{tabular}{|c|c|c|c|c|c|c|c|}
\hline Rank & Journal & $\begin{array}{l}\text { Publication } \\
\text { number }\end{array}$ & Citation & $\mathbf{I F}^{\#}$ & Co-cited journal & Co-citation & IF \\
\hline 1 & World Neurosurgery & 168 & 796 & 1.829 & Stroke & 5,721 & 7.19 \\
\hline 3 & Journal of Neurosurgery & 80 & 1,108 & 3.968 & Neurosurgery & 2,410 & 4.853 \\
\hline 6 & Childs Nervous System & 56 & 323 & 1.298 & Clinical Neurology and Neurosurgery & 1,415 & 1.53 \\
\hline 7 & Neurologia medico-chirurgica & 54 & 704 & 1.836 & Neurology & 1,293 & 8.77 \\
\hline 8 & Acta Neurochirurgica & 48 & 522 & 1.817 & New England Journal of Medicine & 1,024 & 74.699 \\
\hline 9 & American Journal of Neuroradiology & 47 & 708 & 3.381 & Acta Neurochirurgica & 986 & 1.817 \\
\hline 10 & Neurosurgery & 45 & 844 & 4.853 & Cerebrovascular Diseases & 948 & 2.698 \\
\hline
\end{tabular}

Data were retrieved from 1,896 publications with VOSviewer on August 14, 2020. ( ${ }^{*}$ Surgical Neurology was renamed World Neurosurgery in 2010).

\#Abbreviation for Impact Factor.

TABLE 4 | The top 12 prolific authors and co-cited authors on MMA research from 2010 to 2019.

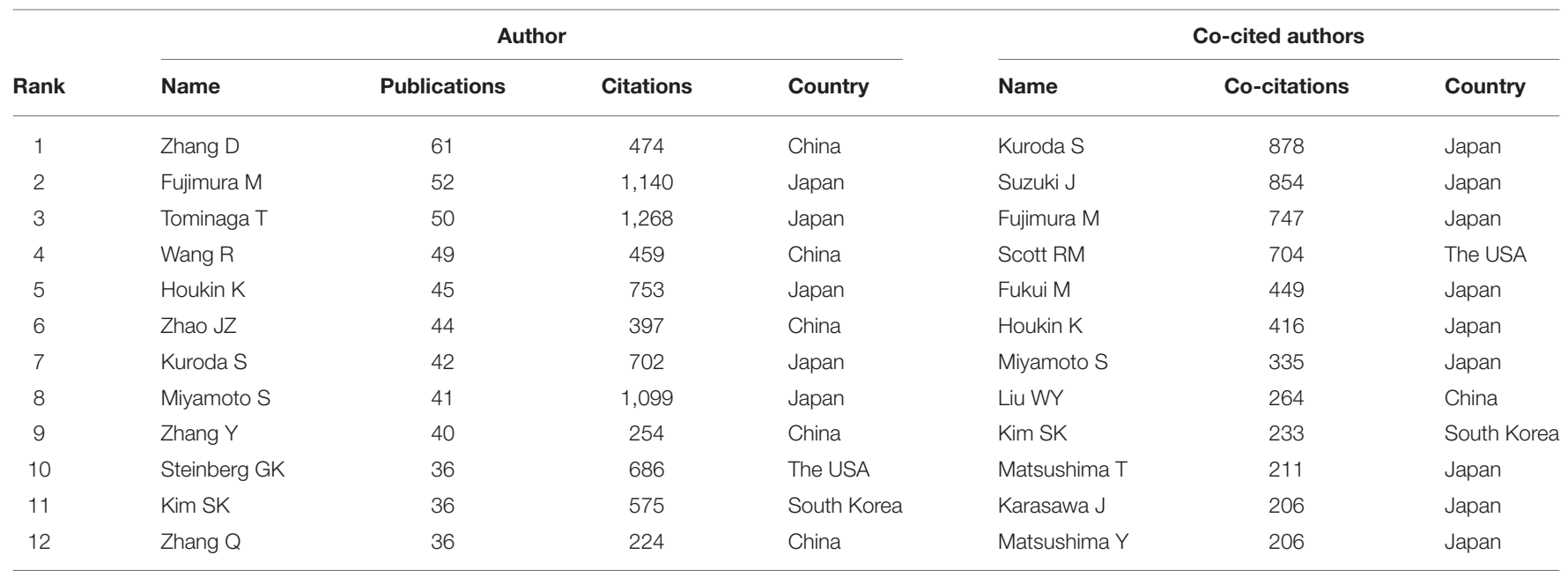

Data were retrieved from 1,896 publications with VOSviewer on August 14, 2020.

in Figure 5A. Figure 5B displays the network map of co-cited authors with more than 230 co-citations. In the map, Kuroda S was the most notable author in terms of co-citations.

\section{Subject Categories}

The map of publication categories (Figure 6) was generated using CiteSpace software. Centrality indicates the importance of an item in CiteSpace. All 1,896 publications were associated with 40 disciplines. The top 10 subject categories ranked by publication or centrality were shown in Table 5, and NEUROSCIENCES AND NEUROLOGY and BIOCHEMISTRY AND MOLECULAR BIOLOGY tied for first.

\section{Keywords}

High-frequency keywords could reflect research hot spots. A thesaurus was used to clean the data, and 4,619 keywords were extracted from the 1,896 publications. Ultimately, 62 keywords with more than 30 occurrences were identified. The top 5 keywords ranked by number of occurrences were as following: moyamoya disease $(n$ $=1,081)$, revascularization $(n=421)$, stroke $(n=372)$, children $(n=331)$, and surgery $(n=258)$. The cooccurrence network of keywords is displayed in Figure 7A. As shown in Figure 7A, the keywords were grouped into four clusters. Notably, the primary keywords for cluster 1 (red) referred to epidemiology and genetics and included epidemiologic features, Japan, prevalence, gene, genetics, and RNF213. Cluster 2 (green) referred to surgical treatments and included revascularization, surgery, pial synangiosis, encephaloduroarteriosynangiosis, synangiosis, and indirect revascularization. Cluster 3 (blue) referred to imaging diagnosis and included blood flow, MRI, hemodynamics, perfusion, PET, cerebrovascular reactivity, and SPECT, and cluster 4 (yellow) referred to clinical presentation and prognosis and comprised hemorrhage, aneurysm, subarachnoid hemorrhage, and natural history. 


\section{A}

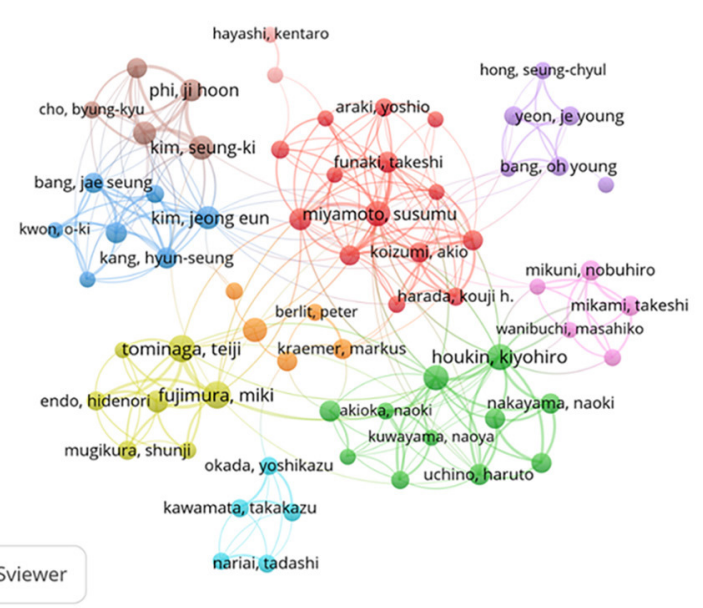

B

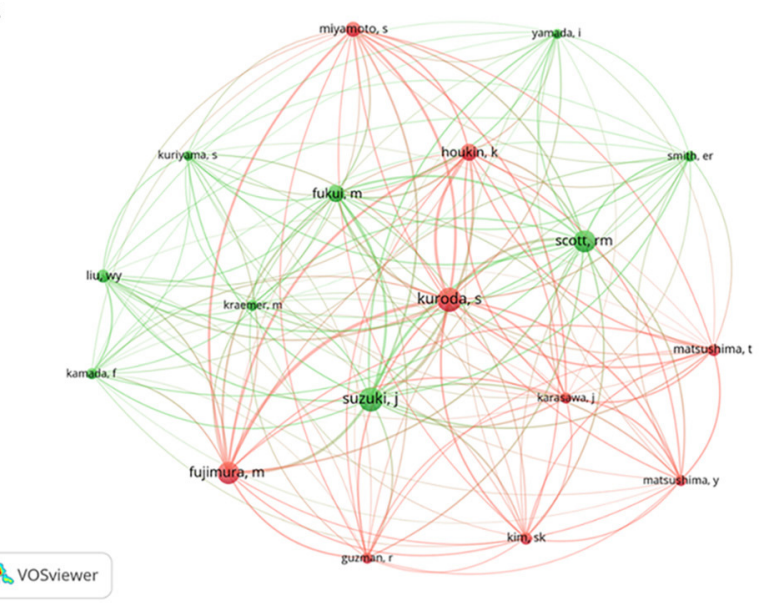

FIGURE 5 | (A) Co-authorship network visualization map of authors on MMA research. (B) Co-citation network visualization map of authors on MMA research.

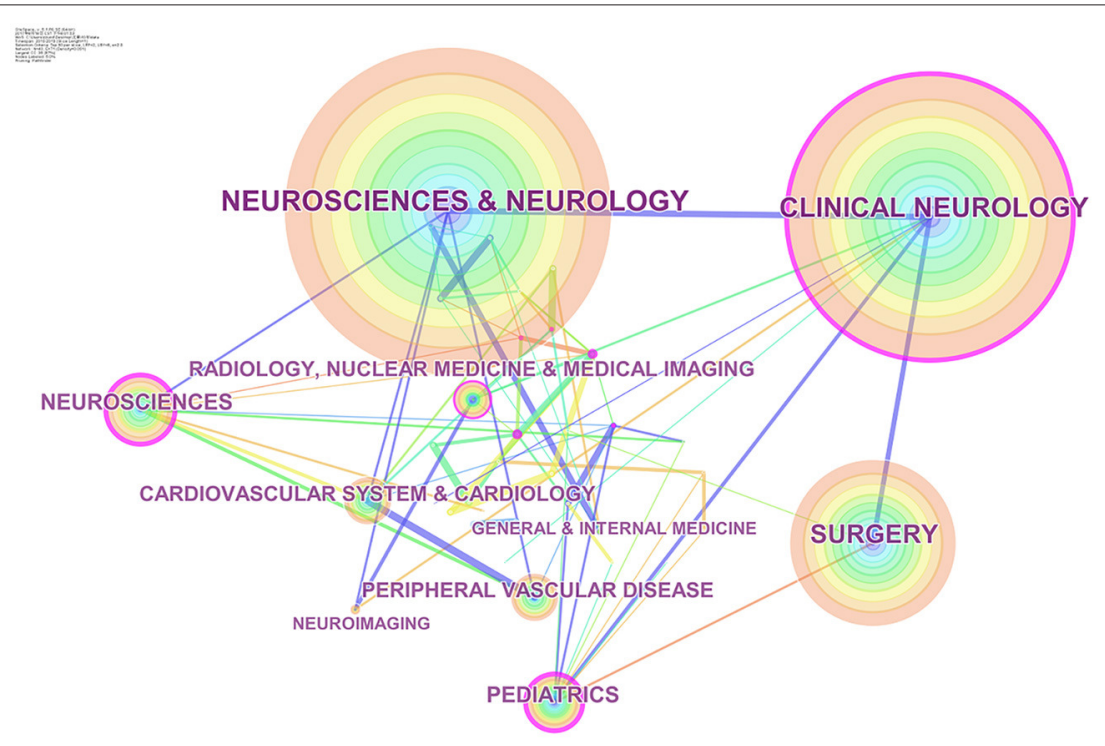

FIGURE 6 | The visualization map of subject categories on MMA. The tree ring-shaped nodes represented different subject categories. The lines between two nodes meant co-occurrence. The area of the nodes referred to the number of publications. Nodes with high centrality (purple ring) were deemed as the hot field.

Burst terms were identified with CiteSpace to indicate new research trends and frontier topics (16). The node type was set as "Keyword," and other parameters were set in accordance with the description in the Materials and Methods section. The minimum duration was set to the default value of 2. As Figure 7B shows, 46 keywords with strong citation bursts were found. Among the top keywords, revascularization surgery had the highest burst strength (8.4439). Other keywords with high burst strengths from 2017 to 2019 include revascularization surgery, cerebral vascular reactivity, outcome, synangiosis, association, and stenosis.

\section{Co-cited References}

Co-cited references were references cited collectively in the reference lists of other literature (17). Among the 1896 publications, 24,041 co-cited references were identified. The top ten co-cited references were presented in Table 6. The article published in Arch Neurol-Chicago (18) written by Suzuki J and colleagues was the most co-cited reference $(n=615)$, followed by the review written by Scott RM in The New England Journal of Medicine $(n=452)$ (2) and the review written by Kuroda $S$ in Lancet Neurology $(n=354)(1)$. References with more than 100 co-citations were used to form a co-citation network map. In Figure 8A, the study published in Arch Neurol-Chicago (18) has the highest weight and an active relationship with other studies.

Citation bursts can be analyzed by identifying references that researchers focused on during certain periods of time (26). References with the strongest citation bursts were identified using CiteSpaceV, and the minimum burst duration was confined to 
TABLE 5 | Top 10 subject categories in terms of publication number and centrality related to MMA research.

\begin{tabular}{cclll}
\hline Rank & Publications & Category & Centrality & Category \\
\hline 1 & 1,364 & NEUROSCIENCES AND NEUROLOGY & 0.37 & BIOCHEMISTRY AND MOLECULAR BIOLOGY \\
2 & 1,188 & CLINICAL NEUROLOGY & 0.35 & PEDIATRICS \\
3 & 710 & SURGERY & 0.25 & CLINICAL NEUROLOGY \\
4 & 302 & NEUROSCIENCES & 0.23 & BIOPHYSICS \\
5 & 256 & PEDIATRICS & 0.21 & NEUROSCIENCES \\
6 & 237 & CARDIOVASCULAR SYSTEM AND CARDIOLOGY & 0.19 & RADIOLOGY, NUCLEAR MEDICINE \& MEDICAL IMAGING \\
7 & 224 & PERIPHERAL VASCULAR DISEASE & 0.18 & HEMATOLOGY \\
8 & 184 & RADIOLOGY, NUCLEAR MEDICINE AND MEDICAL IMAGING & 0.18 & CELL BIOLOGY \\
9 & 83 & NEUROIMAGING & 0.13 & CARDIAC AND CARDIOVASCULAR SYSTEMS \\
10 & 74 & GENERAL AND INTERNAL MEDICINE & 0.09 & CARDIOVASCULAR SYSTEM AND CARDIOLOGY \\
& & & & GENETICS AND HEREDITY
\end{tabular}

Data were retrieved from 1,896 publications with CiteSpaceV on August 14, 2020.

A

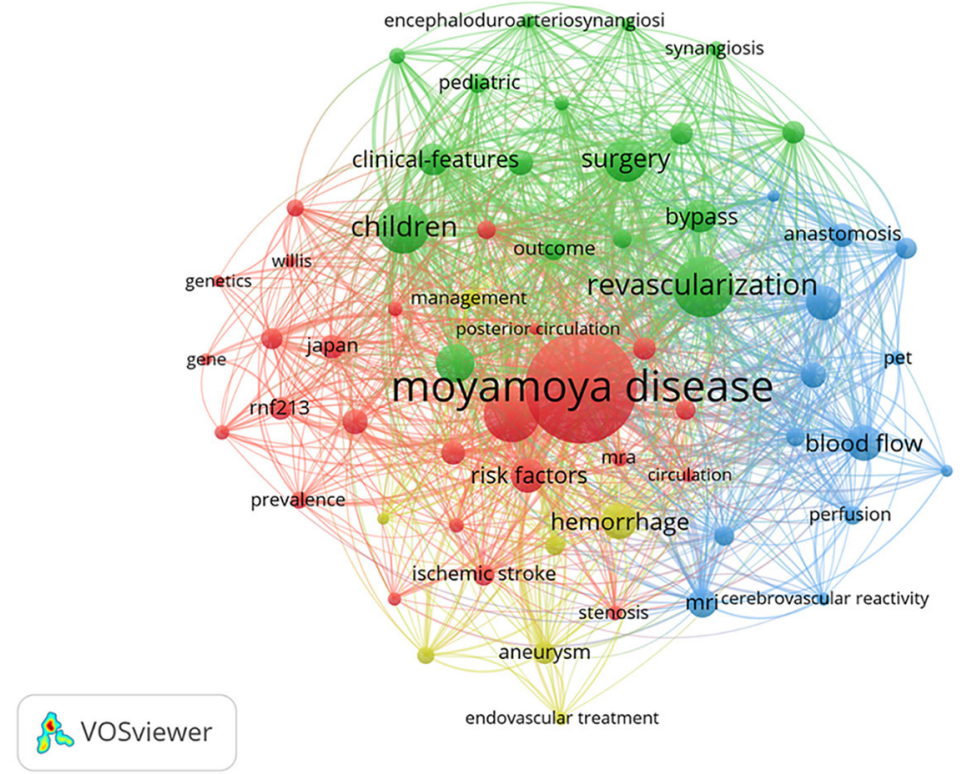

\section{Top 46 Keywords with the Strongest Citation Bursts}

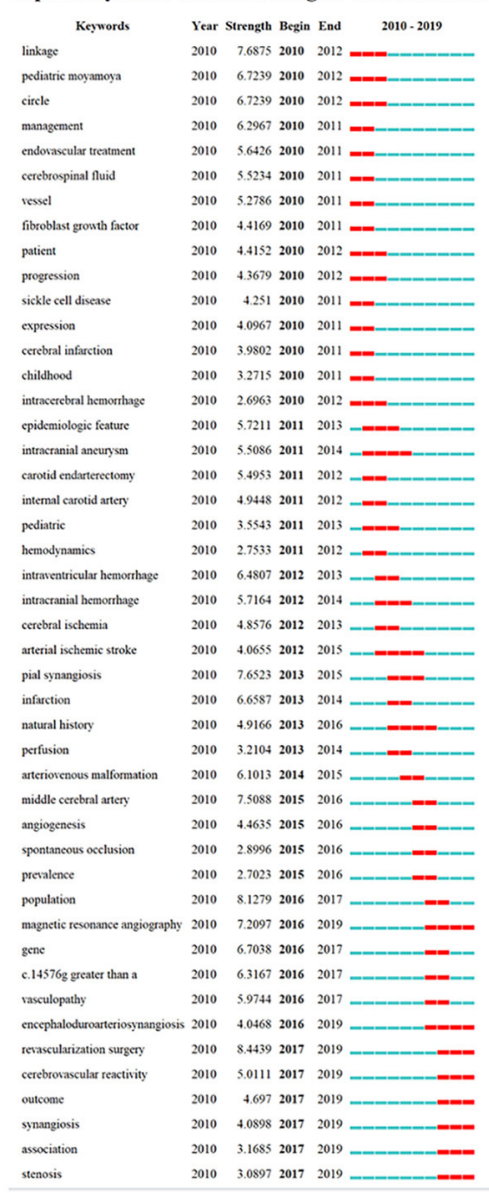

FIGURE 7 | (A) The co-occurrence network visualization map of keywords in the MMA research field from 2010 to 2019. Keywords in the same color represent were sorted into the same cluster. (B) The top 46 keywords with the strongest citation bursts on MMA research between 2010 and 2019. The red segment of the blue line denoted the burst duration of a keyword. 
4 years. The node type was set as "Cited Reference," and the other parameters were set in accordance with the description in the Materials and Methods section. As shown in Figure 8B, burst strength values of the top 25 references with the strongest citation bursts ranged from 2.9728 to 18.0315 . "Hallemeier CL, 2006, Stroke, V37, P1490 (27)" had the highest burst strength (18.0315), and three co-cited references had recent bursts: "Dusick JR, 2011, Neurosurgery, V68, P34 (28)," "Bao XY, 2012, Cerebrovasc Dis, V34, P305 (29)," and "Sonobe S, 2014, Brain Res, V1552, P64 (30)." Significantly, the third article by Sonobe S showed the highest burst strength (8.5243) among studies with citation bursts ending in 2019. Dusick JR demonstrated that indirect revascularization surgeries by encephaloduroarteriosynangiosis (EDAS) and multiple burrhole operation provided effective prevention for recurrent

TABLE 6 | The top 10 co-cited reference with regard to MMA during 2010-2019.

\begin{tabular}{clc}
\hline Rank & Co-cited reference & Count \\
\hline 1 & Suzuki J, 1969, Arch Neurol-Chicago, V20, P288 (18) & 615 \\
2 & Scott RM, 2009, New Engl J Med, V360, P1226 (2) & 452 \\
3 & Kuroda S, 2008, Lancet Neurol, V7, P1056 (1) & 354 \\
4 & Fukui M, 1997, Clin Neurol Neurosur, V99, PS238 (19) & 269 \\
5 & Scott RM, 2004, J Neurosurg, V100, P142 (20) & 204 \\
6 & Kamada F, 2011, J Hum Genet, V56, P34 (21) & 193 \\
7 & Suzuki J, 1983, Stroke, V14, P104 (22) & 190 \\
8 & Liu WY, 2011, PLoS ONE, V6 (23) & 188 \\
9 & Guzman R, 2009, J Neurosurg, V111, P927 (24) & 187 \\
10 & Kuriyama S, 2008, Stroke, V39, P42 (25) & 166 \\
\hline
\end{tabular}

Data were retrieved from 1,896 publications with VOSviewer on August 14, 2020. ischemia and hemorrhage in 95\% children and adults (28). Bao XY revealed EDAS in Chinese adult patients with MMD was relatively safe and effective at preventing future ischemia and improving quality of life (29). SONOBE S and colleagues found that the functional deficiency of RNF213 did not sufficiently cause the emergence of the MMD-like phenotype (30).

Revascularization surgery researches and RNF213related researches were selected as recent frontier topics. "Revascularization surgery" had the highest burst strength among the six recent keywords. It was also described in the first article with citation bursts ending in 2019 by Dusick JR (28). "RNF213" was discussed in the third article by Sonobe S (30), which also represented the hot spots of MMA.

\section{DISCUSSION}

Although MMA is a rare cerebrovascular disease, it is one of the main causes of pediatric and young adult stroke $(31,32)$. The etiology and pathogenesis mechanisms of MMA remained unclear, and there is currently a lack of effective medical treatments. Surgical intervention is currently the main therapeutic strategy. However, surgical treatment mainly aims to improve cerebral hypoperfusion rather than combat the pathogenic mechanisms (33). Timely diagnosis and early intervention have benefitted MMA patients (34), but it is still necessary to establish a sufficient understanding of this disease. Therefore, we made a novel attempt to examine MMA publications from 2010 to 2019 and to provide a full view of the research trends by using a bibliometric analysis.

The data of annual output and growth rate could reflect the development of a given research area in terms of scientific data.

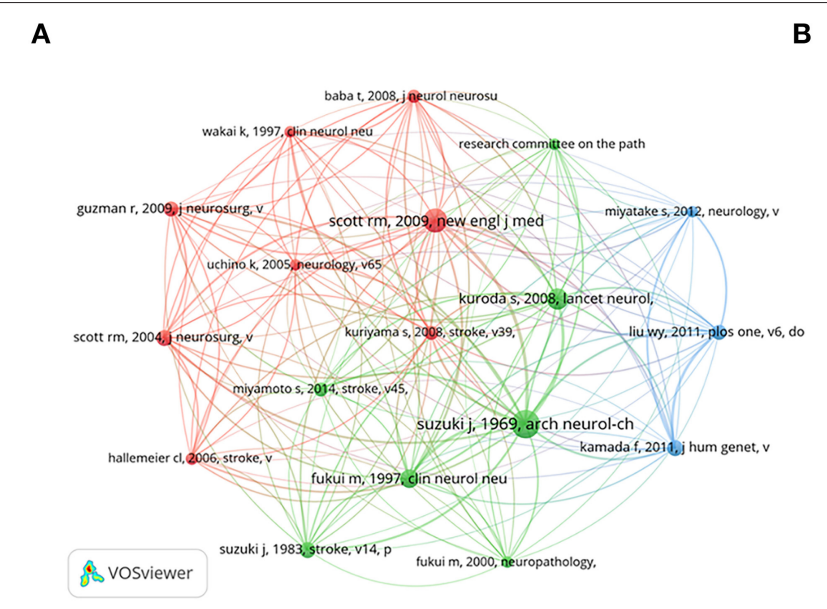

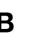

\begin{tabular}{|c|c|c|c|c|}
\hline \multicolumn{5}{|c|}{ Top 25 References with the Strongest Citation Bursts } \\
\hline References & & Strength Begin & & $2010-2019$ \\
\hline KAGI Y, 2007, NEUROL MED.CHIR, V47, P1, DOI & 2007 & 6.63652010 & 2013 & \\
\hline SAINTE-ROSE C, 2006, J NEUROSURG, V105, P437, DOI & 2006 & 6.63652010 & 2013 & \\
\hline UCHINO K, 2005, NEUROLOGY, V65, P956, DOI & 2005 & 15.1992010 & 2013 & \\
\hline KURODA S, 2005, STROKE, V36, P2148, DOl & 2005 & $12.2102 \quad 2010$ & 2013 & \\
\hline KURIYAMA S, 2008, STROKE, V39, P42, DOI & 2008 & 3.97812010 & 2014 & \\
\hline ACHROL AS, 2009, NEUROSURG FOCUS, V26, PO, DOI & 2009 & 4.85142010 & 2013 & \\
\hline HALLEMEIER CL., 2006, STROKE, V37, P1490, DOI & 2006 & $18.0315 \quad 2010$ & 2014 & \\
\hline MINEHARU Y, 2006, J NEUROL, NEUROSUR PS, V77, P1025, DOI & 2006 & 6.41882010 & 2014 & \\
\hline WOIZZIK J, 2005, J NEUROSURG, V102, P692, DOI & 2005 & 4.41812010 & 2013 & \\
\hline ROSSER TL, 2005, NEUROL.OGY, V64, PS53, DOI & 2005 & 7.00682010 & 2013 & \\
\hline FUNG LLWE, 2005, CHILD NERV SYST, V21, P358, DOI & 2005 & 11.46472010 & 2013 & \\
\hline KELLY ME, 2006, CEREBROVASC DIS, V22, P109, DOI & 2006 & 10.92432010 & 2014 & \\
\hline ROACH ES, 2008, STROKE, V39, P2644, DOI & 2008 & 8.40092010 & 2015 & \\
\hline FUJMURA M, 2009, SURG NEUROL, V71, P442, DOI & 2009 & 5.35122010 & 2014 & \\
\hline FUתMURA M, 2007, SURG NEUROL, V67, P273, DOI & 2007 & 7.49962011 & 2015 & \\
\hline LEE M, 2009, NEUROSURG FOCUS, V26, P0, DOI & 2009 & 6.87432011 & 2014 & \\
\hline STARKE RM, 2009, J NEUROSURG, V111, P936, DOI & 2009 & 9.09372011 & 2014 & \\
\hline MESIWALA AH, 2008, NEUROSURG FOCUS, V24, PO, DOI & 2008 & 3.85842011 & 2015 & \\
\hline LUU W, 2010, ENVIRONMENTAL HEALTH AND PREVENTIVE MEDICINE, V15, P94, DOI & 2010 & 5.55682012 & 2015 & \\
\hline OHUE S, 2008, SURG NEUROL, V69, P281, DOI & 2008 & 5.55682012 & 2015 & \\
\hline BABA T, 2008, J NEUROL NEUROSUR PS, V79, P900, DOI & 2008 & 11.30982012 & 2015 & \\
\hline DUSICK R, 2011, NEUROSURGERY, V68, P34, DOI & 2011 & 2.97282013 & 32019 & \\
\hline KIM SJ, 2010, STROKE, V41, P173, DOl & 2010 & 8.23782013 & 2016 & \\
\hline BAO XY, 2012, CEREBROVASC DIS, V34, P305, DOI & 2012 & 3.05482014 & 2019 & \\
\hline SONOBE S, 2014, BRAIN RES, V1552, P64, DO1 & 2014 & 8.52432015 & 52019 & \\
\hline
\end{tabular}

FIGURE 8 | (A) The Co-citation network visualization map of references on MMA research between 2010 and 2019 . (B) The top 25 references with the strongest citation bursts on MMA research between 2010 and 2019. The red segment of the blue line denoted the burst duration of a keyword. 
In 2011, RNF213 was reported as the first susceptibility gene by Kamada F et al. and Liu WY et al. respectively $(21,23)$. This discovery advanced the study of genetic factors in MMD pathogenesis. More RNF213-related articles were published after 2011. These two articles were also shown in Table 6. This may be the reason why the growth rate rapidly increased in 20112012. And in 2012, Japan released new guidelines for diagnosis and treatment of MMD (35). This guideline was recognized worldwide and drove research discovery in related area.

Japan, China, and South Korea belong to the same cluster, as shown in Figure 3, and they were ranked the highest in Table 1. Furthermore, nine of the top 10 productive institutions were in East Asian countries, which shows that East Asian institutions occupied key positions in MMA research, which is consistent with the epidemiological understanding that MMA has a higher incidence rate in East Asia (36).

As shown in Table 3, World Neurosurgery had the largest number of publications, and STROKE had the most cocited article. An understanding of prolific journals could help researchers choose journals for draft submissions, and publications from top co-cited journals could be used as authoritative references. Moreover, there were six journals that were in both the top 10 prolific journals and the top 10 co-cited journals: World Neurosurgery, Journal of Neurosurgery, Stroke, Acata Neurochirurgica, American Journal of Neuroradiology, and Neurosurgery. All six journals were strongly recommended by researchers in the field.

In terms of subjects in Figure 6 and Table 5, NEUROSCIENCES AND NEUROLOGY and BIOCHEMISTRY AND MOLECULAR BIOLOGY occupied pivotal positions in this field, indicating that both clinical practice and mechanism-related studies were of vital importance for MMA research.

Generally, a co-cited reference that ranked higher represented an "intellectual base" in this area $(9,37)$. These publications could provide a foundation for scholars who want to acquire quick insight in a particular field.

As shown in Result section, revascularization surgery and RNF213 were chosen as recent frontier topics in our study.

(1) Revascularization surgery played a significant role in the treatment of MMA patients. Surgical revascularization surgeries could be divided into direct revascularization, indirect revascularization, and the combination of both (38). As for adult patients with MMD, direct revascularization and combined revascularization were recommended (39, 40). Indirect revascularization was feasible for certain patient subgroups such as pediatric patients as well (41). The Japanese MMD trial (JAM) by Miyamoto S, et al. provided the highest-level evidence of the preventive effect of direct anastomosis for hemorrhagic MMD (42). Remarkably, the paper appeared in Figure 8A.

There were still some lingering questions remained to be elucidated. Although revascularization surgery might well be the most effective method for ischemic MMD in clinical practice, randomized clinical trials were still lacking $(43,44)$. The small sample size and lacking of neurological function assessment restrained the clinical applications of the JAM trial. Besides, ischemic events, especially transient ischemic attacks, were the main clinical manifestation for children and hemorrhagic stroke was more generally seen in adults (45-47). The occurrence rate of hemorrhagic stroke in adults varied among different region (47). Furthermore, cognition preservation was also of great importance. Revascularization surgery has been proved to be beneficial to patients with concomitant cognitive impairment (48), while a recent study revealed that cerebral hyperperfusion in the acute phase after revascularization surgery could result in cognitive impairment (49). Comprehensive evaluation and precise diagnosis were desperately needed to provide reliable basis for surgery opportunity choice and clinical treatments. Hence, large scale multicenter and multination RCTs were needed to illustrate the role of revascularization surgery among various populations of different epidemiological backgrounds. However, it was noteworthy that RCTs for ischemic MMD were ethically difficult to be carried out. Ongoing trials, such as the Adult Hemorrhagic Moyamoya Surgery Study (AHMMS), might provide insights to some of these questions (50). The aim of the AHMSS study was to replicate the therapeutic efficacy for preventing rebleeding in Chinese adult patients with hemorrhagic MMD and to reveal whether extracranialintracranial (EC-IC) bypass surgery could improve neurological function, which was not evaluated in the JAM trial.

(2) MMA has been reported to be related to genetic factors, and numerous studies have revealed that the RNF213 gene on chromosome $17 \mathrm{q} 25.3$ played a role in the pathogenesis of MMA (51). Screening for RNF213 gene susceptibility to MMA patients and their families might provide evidence for the early diagnosis of MMA disease (52). A variant in RNF213 that altered arginine at position 4810 (p.R4810K) was associated with MMD in Asian populations. The homozygote of the p.R4810K variant on RNF213 exhibited an early onset age and severe form of moyamoya disease (53). Alterations in RNF213 predisposed patients of diverse ethnicities to MMD, but the p.R4810K variant predisposed individuals of Asian populations only (54). R4810K was an AAA(+) ATPase and decreased ATPase activity, suggesting its antiangiogenic activity through stabilizing oligomers. Therefore, a specific inhibitor of ATP binding to the first $\mathrm{AAA}(+)$ could be a promising therapeutic candidate for MMD (55).

This article also had some limitations:

1) Publication bias: To match the data type requirements of scientometric tools such as CiteSpace and VOSviewer, we extracted data from WoSCC, one of the most extensive and comprehensive global databases and the most commonly used source of publications in scientometry. Articles not indexed in WoSCC could not be involved in our study. As a result, the bias is hard to be avoided objectively.

2) Language bias: Identified literature were primarily published in English (ratio $=0.9879$ ) which might lead to a language bias. English was not the main language used in East Asia, where MMA had a high incidence rate. MMA research written in Chinese, Japanese, and Korean had high reference value. 
3) The larger number of publications was not always more important or informative. Researchers were recommended to pay attention to both the quantity of publications and their citation when they followed certain authors or institutions.

Bibliometric analysis could be used as a synopsis to help researchers to gain initial and general insights into a specific field. With the expansion of researchers' exploration of MMA, the hot spots of research on MMA have gradually changed. The brief contrasts between bibliometric data in 2000-2009 and 2010-2019 have been presented in Supplementary Material. Despite certain limitations, our study provided a comprehensive assessment and a preliminary understanding of the trends in MMA research. We sincerely hope that bibliometric and visualization-based analyses of global literature can provide an in-depth view of the disease mechanisms, epidemiology and treatments.

\section{Prospects}

To our knowledge, this article presents the first bibliometric study that systematically analyses the global trends in MMA research over the past 10 years. This analysis could guide scholars in the selection of new research directions and help them to understand research hot spots and frontiers. Hopefully, high-quality clinical evidence will be obtained in the future. Further cooperation between authors, institutions and countries is expected to accelerate the treatment of MMA.

\section{REFERENCES}

1. Kuroda S, Houkin K. Moyamoya disease: current concepts and future perspectives. Lancet Neurol. (2008) 7:1056-66. doi: 10.1016/S1474-4422(08)70240-0

2. Scott RM, Smith ER. Moyamoya disease and moyamoya syndrome. $N$ Engl J Med. (2009) 360:1226-37. doi: 10.1056/NEJMra0804622

3. Larson A, Rinaldo L, Lanzino G, Klaas JP. High prevalence of prothrombotic conditions in adult patients with moyamoya disease and moyamoya syndrome: a single center study. Acta Neurochir. (2020) 162:18539. doi: 10.1007/s00701-020-04420-8

4. Chen SX, Lu Q, Bai JB, Deng CY, Wang YG, Zhao Y. Global publications on stigma between 1998-2018: a bibliometric analysis. J Affect Disord. (2020) 274:363-71. doi: 10.1016/j.jad.2020.05.006

5. Guo SM, Wang L, Xie YJ, Luo X, Zhang SJ, Xiong LB, et al. Bibliometric and visualized analysis of stem cells therapy for spinal cord injury based on Web of Science and CiteSpace in the last 20 years. World Neurosurg. (2019) 132:E246-58. doi: 10.1016/j.wneu.2019. 08.191

6. Leng $\mathrm{Z}, \mathrm{He} \mathrm{X}$, Li $\mathrm{H}$, Wang $\mathrm{D}$, Cao K. Olfactory ensheathing cell transplantation for spinal cord injury: an 18-year bibliometric analysis based on the Web of Science. Neural Regen Res. (2013) 8:1286-96. doi: 10.3969/j.issn.1673-5374.2013.14.005

7. Garfield E, Paris SW, Stock WG. HistCite ${ }^{\mathrm{TM}}$ : a software tool for informetric analysis of citation linkage. Information-Wissenschaft und Praxis. (2006) 57:391-400.

8. van Eck NJ, Waltman L. Software survey: VOSviewer, a computer program for bibliometric mapping. Scientometrics. (2010) 84:523-38. doi: 10.1007/s11192-009-0146-3

\section{DATA AVAILABILITY STATEMENT}

The original contributions presented in the study are included in the article/Supplementary Material, further inquiries can be directed to the corresponding author/s.

\section{AUTHOR CONTRIBUTIONS}

DC and GZ: study conception, design and data analysis. DC: paper writing. JiaW, SC, JinW, HN, and ZT: language polishing, paper review and editing. All authors read and approved the final version of the paper.

\section{FUNDING}

This work was supported by Grant 82071330 and Grant 81873750 from National Natural Science Foundation of China (ZT).

\section{ACKNOWLEDGMENTS}

We thank QZ for assistance with manuscript preparation.

\section{SUPPLEMENTARY MATERIAL}

The Supplementary Material for this article can be found online at: https://www.frontiersin.org/articles/10.3389/fneur. 2021.637310/full\#supplementary-material

9. Chen C. CiteSpace II: detecting and visualizing emerging trends and transient patterns in scientific literature. J Am Soc Inf Sci Technol. (2006) 57:359-77. doi: 10.1002/asi.20317

10. Akmal M, Hasnain N, Rehan A, Iqbal U, Hashmi S, Fatima K, et al. Glioblastome multiforme: a bibliometric analysis. World Neurosurg. (2020) 136:270-82. doi: 10.1016/j.wneu.2020.01.027

11. Thompson DF, Walker CK. A descriptive and historical review of bibliometrics with applications to medical sciences. Pharmacotherapy. (2015) 35:551-9. doi: 10.1002/phar.1586

12. Xie L, Chen Z, Wang H, Zheng C, Jiang J. Bibliometric and visualized analysis of scientific publications on atlantoaxial spine surgery based on Web of Science and VOSviewer. World Neurosurg. (2020) 137:435-42.e4. doi: 10.1016/j.wneu.2020.01.171

13. Moher D, Liberati A, Tetzlaff J, Altman DG, Group P. Preferred reporting items for systematic reviews and meta-analyses: the PRISMA statement. PLoS Med. (2009) 6:e1000097. doi: 10.1371/journal.pmed.1000097

14. Yang C, Wang X, Tang X, Bao X, Wang R. Research trends of stem cells in ischemic stroke from 1999 to 2018: a bibliometric analysis. Clin Neurol Neurosurg. (2020) 192:105740. doi: 10.1016/j.clineuro.2020. 105740

15. Wang R, Weng LM, Peng MS, Wang XQ. Exercise for low back pain: a bibliometric analysis of global research from 1980 to 2018. J Rehabil Med. (2020) 52:jrm00052. doi: 10.2340/16501977-2674

16. Zhou H, Tan W, Qiu Z, Song Y, Gao S. A bibliometric analysis in gene research of myocardial infarction from 2001 to 2015. PeerJ. (2018) 6:e4354. doi: $10.7717 /$ peerj. 4354

17. Lu C, Li X, Yang $\mathrm{K}$. Trends in shared decision-making studies From 2009 to 2018: a bibliometric analysis. Front Public Health. (2019) 7:384. doi: $10.3389 /$ fpubh.2019.00384 
18. Suzuki J, Takaku A. Cerebrovascular "moyamoya" disease. Disease showing abnormal net-like vessels in base of brain. Arch Neurol. (1969) 20:288-99. doi: 10.1001/archneur.1969.00480090076012

19. Fukui M. Guidelines for the diagnosis and treatment of spontaneous occlusion of the circle of Willis ("moyamoya" disease). Research committee on spontaneous occlusion of the circle of Willis (moyamoya disease) of the Ministry of Health and Welfare, Japan. Clin Neurol Neurosurg. (1997) 99(Suppl. 2):S238-40. doi: 10.1152/ajpendo.00237.2011

20. Scott RM, Smith JL, Robertson RL, Madsen JR, Soriano SG, Rockoff MA. Long-term outcome in children with moyamoya syndrome after cranial revascularization by pial synangiosis. J Neurosurg. (2004) 100(2 Suppl Pediatrics):142-9. doi: 10.3171/ped.2004.100.2.0142

21. Kamada F, Aoki Y, Narisawa A, Abe Y, Komatsuzaki S, Kikuchi A, et al. A genome-wide association study identifies RNF213 as the first Moyamoya disease gene. J Hum Genet. (2011) 56:34-40. doi: 10.1038/jhg.2010.132

22. Suzuki J, Kodama N. Moyamoya disease-a review. Stroke. (1983) 14:104-9. doi: 10.1161/01.str.14.1.104

23. Liu W, Morito D, Takashima S, Mineharu Y, Kobayashi H, Hitomi T, et al. Identification of RNF213 as a susceptibility gene for moyamoya disease and its possible role in vascular development. PLoS ONE. (2011) 6:e22542. doi: 10.1371/journal.pone.0022542

24. Guzman R, Lee M, Achrol A, Bell-Stephens T, Kelly M, Do HM, et al. Clinical outcome after 450 revascularization procedures for moyamoya disease. Clinical article. J Neurosurg. (2009) 111:927-35. doi: 10.3171/2009.4.JNS081649

25. Kuriyama S, Kusaka Y, Fujimura M, Wakai K, Tamakoshi A, Hashimoto S, et al. Prevalence and clinicoepidemiological features of moyamoya disease in Japan: findings from a nationwide epidemiological survey. Stroke. (2008) 39:42-7. doi: 10.1161/STROKEAHA.107.490714

26. Huang $X$, Fan $X$, Ying J, Chen S. Emerging trends and research foci in gastrointestinal microbiome. J Transl Med. (2019) 17:67. doi: 10.1186/s12967-019-1810-x

27. Hallemeier CL, Rich KM, Grubb RL Jr, Chicoine MR, Moran CJ, Cross DT III, et al. Clinical features and outcome in North American adults with moyamoya phenomenon. Stroke. (2006) 37:1490-6. doi: 10.1161/01.STR.0000221787.70503.ca

28. Dusick JR, Gonzalez NR, Martin NA. Clinical and angiographic outcomes from indirect revascularization surgery for Moyamoya disease in adults and children: a review of 63 procedures. Neurosurgery. (2011) 68:34-43. discussion. doi: 10.1227/NEU.0b013e3181fc5ec2

29. Bao XY, Duan L, Li DS, Yang WZ, Sun WJ, Zhang ZS, et al. Clinical features, surgical treatment and long-term outcome in adult patients with Moyamoya disease in China. Cerebrovasc Dis. (2012) 34:305-13. doi: 10.1159/000343225

30. Sonobe S, Fujimura M, Niizuma K, Nishijima Y, Ito A, Shimizu H, et al. Temporal profile of the vascular anatomy evaluated by $9.4-\mathrm{T}$ magnetic resonance angiography and histopathological analysis in mice lacking RNF213: a susceptibility gene for moyamoya disease. Brain Res. (2014) 1552:64-71. doi: 10.1016/j.brainres.2014.01.011

31. Jangra A, Choi SA, Koh EJ, Moon YJ, Wang KC, Phi JH, et al. Panobinostat, a histone deacetylase inhibitor, rescues the angiogenic potential of endothelial colony-forming cells in moyamoya disease. Childs Nerv Syst. (2019) 35:82331. doi: 10.1007/s00381-019-04099-y

32. Zhao M, Deng X, Gao F, Zhang D, Wang S, Zhang Y, et al. Ischemic Stroke in Young Adults with Moyamoya Disease: prognostic Factors for Stroke Recurrence and Functional Outcome after Revascularization. World Neurosurg. (2017) 103:161-7. doi: 10.1016/j.wneu.2017.03.146

33. Matsushima T, Inoue T, Suzuki SO, Fujii K, Fukui M, Hasuo K. Surgical treatment of moyamoya disease in pediatric patients-comparison between the results of indirect and direct revascularization procedures. Neurosurgery. (1992) 31:401-5. doi: 10.1227/00006123-199209000-00003

34. Hirano Y, Miyawaki S, Imai H, Hongo H, Ohara K, Dofuku S, et al. Association between the onset pattern of adult moyamoya disease and risk factors for stroke. Stroke. (2020) 51:3124-8. doi: 10.1161/STROKEAHA.120.030653

35. Research Committee on the Pathology and Treatment of Spontaneous Occlusion of the Circle of Willis, Health Labour Sciences Research Grant for Research on Measures for Infractable Diseases. Guidelines for diagnosis and treatment of moyamoya disease (spontaneous occlusion of the circle of Willis). Neurol Med Chir. (2012) 52:245-66. doi: 10.2176/nmc.52.245
36. Shang S, Zhou D, Ya J, Li S, Yang Q, Ding Y, et al. Progress in moyamoya disease. Neurosurg Rev. (2020) 43:371-82. doi: 10.1007/s10143-018-0994-5

37. Zheng K, Wang X. Publications on the association between cognitive function and pain from 2000 to 2018: a bibliometric analysis using CiteSpace. Med Sci Monit. (2019) 25:8940-51. doi: 10.12659/MSM.917742

38. Zhang $H$, Zheng L, Feng L. Epidemiology, diagnosis and treatment of moyamoya disease. Exp Ther Med. (2019) 17:1977-84. doi: 10.3892/etm.2019.7198

39. Tominaga T, Suzuki N, Miyamoto S, Koizumi A, Kuroda S, Takahashi $\mathrm{J}$, et al. Recommendations for the management of moyamoya disease: a statement from research committee on spontaneous occlusion of the circle of Willis (moyamoya disease) [2nd Edition]. Surg Cereb Stroke. (2018) 46:1-24. doi: $10.2335 /$ scs. 46.1

40. Deng X, Gao F, Zhang D, Zhang Y, Wang R, Wang S, et al. Effects of different surgical modalities on the clinical outcome of patients with moyamoya disease: a prospective cohort study. J Neurosurg. (2018) 128:132737. doi: 10.3171/2016.12.JNS162626

41. Kazumata $\mathrm{K}$. Which is the optimal revascularization surgery in moyamoya disease? World Neurosurg. (2020) 139:616-7. doi: 10.1016/j.wneu.2020. 05.007

42. Miyamoto S, Yoshimoto T, Hashimoto N, Okada Y, Tsuji I, Tominaga T, et al. Effects of extracranial-intracranial bypass for patients with hemorrhagic moyamoya disease: results of the Japan Adult Moyamoya Trial. Stroke. (2014) 45:1415-21. doi: 10.1161/STROKEAHA.113.004386

43. Acker G, Fekonja L, Vajkoczy P. Surgical management of moyamoya disease. Stroke. (2018) 49:476-82. doi: 10.1161/STROKEAHA.117.018563

44. Lee SU, Oh CW, Kwon OK, Bang JS, Ban SP, Byoun HS, et al. Surgical treatment of adult moyamoya disease. Curr Treat Options Neurol. (2018) 20:22. doi: 10.1007/s11940-018-0511-8

45. Kim SK, Cho BK, Phi JH, Lee JY, Chae JH, Kim KJ, et al. Pediatric moyamoya disease: an analysis of 410 consecutive cases. Ann Neurol. (2010) 68:92-101. doi: 10.1002/ana.21981

46. Kim SK, Seol HJ, Cho BK, Hwang YS, Lee DS, Wang KC. Moyamoya disease among young patients: its aggressive clinical course and the role of active surgical treatment. Neurosurgery. (2004) 54:840-4. discussion: 4-6. doi: 10.1227/01.neu.0000114140.41509.14

47. Kim JS. Moyamoya disease: epidemiology, clinical features, and diagnosis. $J$ Stroke. (2016) 18:2-11. doi: 10.5853/jos.2015.01627

48. Lee JY, Phi JH, Wang KC, Cho BK, Shin MS, Kim SK. Neurocognitive profiles of children with moyamoya disease before and after surgical intervention. Cerebrovasc Dis. (2011) 31:230-7. doi: 10.1159/0003 21901

49. Yanagihara W, Chida K, Kobayashi M, Kubo Y, Yoshida K, Terasaki $\mathrm{K}$, et al. Impact of cerebral blood flow changes due to arterial bypass surgery on cognitive function in adult patients with symptomatic ischemic moyamoya disease. J Neurosurg. (2018) 131:1716-24. doi: 10.3171/2018.7.JNS 18149

50. ClinicalTrials.gov. Huashan Hospital. The Adult Hemorrhagic Moyamoya Surgery Study (AHMSS). (2016). Available online at: https://clinicaltrials.gov/ ct2/show/NCT02319980 (accessed January 17, 2021).

51. Koizumi A, Kobayashi H, Hitomi T, Harada KH, Habu T, Youssefian S. A new horizon of moyamoya disease and associated health risks explored through RNF213. Environ Health Prev Med. (2016) 21:55-70. doi: 10.1007/s12199-015-0498-7

52. Matsuda Y, Mineharu Y, Kimura M, Takagi Y, Kobayashi H, Hitomi T, et al RNF213 p.R4810K variant and intracranial arterial stenosis or occlusion in relatives of patients with moyamoya disease. J Stroke Cerebrovasc Dis. (2017) 26:1841-7. doi: 10.1016/j.jstrokecerebrovasdis.2017.04.019

53. Miyatake S, Miyake N, Touho H, Nishimura-Tadaki A, Kondo Y, Okada I, et al. Homozygous c.14576G $>$ A variant of RNF213 predicts earlyonset and severe form of moyamoya disease. Neurology. (2012) 78:803-10. doi: 10.1212/WNL.0b013e318249f71f

54. Cecchi AC, Guo D, Ren Z, Flynn K, Santos-Cortez RL, Leal SM, et al. RNF213 rare variants in an ethnically diverse population with moyamoya disease. Stroke. (2014) 45:3200-7. doi: 10.1161/STROKEAHA.114. 006244

55. Kobayashi H, Matsuda Y, Hitomi T, Okuda H, Shioi H, Matsuda T, et al. Biochemical and functional characterization of RNF213 (Mysterin) R4810K, 
a susceptibility mutation of moyamoya disease, in angiogenesis in vitro and in vivo. J Am Heart Assoc. (2015) 4:e002146. doi: 10.1161/JAHA.115.0 02146

Conflict of Interest: The authors declare that the research was conducted in the absence of any commercial or financial relationships that could be construed as a potential conflict of interest.
Copyright $\odot 2021$ Chen, Zhang, Wang, Chen, Wang, Nie and Tang. This is an open-access article distributed under the terms of the Creative Commons Attribution License (CC BY). The use, distribution or reproduction in other forums is permitted, provided the original author(s) and the copyright owner(s) are credited and that the original publication in this journal is cited, in accordance with accepted academic practice. No use, distribution or reproduction is permitted which does not comply with these terms. 